\title{
PATTERNS OF SLEEP IMPAIRMENTS IN AN EPIDEMIOLOGICAL COHORT OF POSTMENOPAUSAL WOMEN IN PERUNDURAI
}

\author{
M. Indira ${ }^{1}$, P. Kasikrishnaraja ${ }^{2}$
}

${ }_{1}^{1}$ Assistant Professor, Department of Obstetrics and Gynaecology, IRT-Perundurai Medical College, Erode, Tamilnadu.

${ }^{2}$ Associate Professor, Department of Psychiatry, IRT-Perundurai Medical College, Erode, Tamilnadu.

\begin{abstract}
BACKGROUND
ABSTRACT

Menopause is cessation of menstruation for one year. Postmenopausal period is an important phase in women's life, in which many psychophysical changes occur. Insomnia is an important issue commonly encountered in the clinical setting in this subset of women in the gynaecology OPD. Variety of sleep pattern changes occur in postmenopausal women. Many women complain of difficulty in initiating and maintaining sleep, frequent sleep fragmentation and early morning awakenings, vivid dreams and nonrestorative sleep. Other sleep disruptions commonly encountered include restless leg syndrome and obstructive sleep apnoea.

Aims \& Objectives-The aim of this study was to identify the patterns of sleep impairments in postmenopausal women. We obtained the data by interviewing 35 postmenopausal women who were presenting to the OPD. The women gave accounts of their difficulties with sleep. A variety of dimensions were identified using the rating scale.
\end{abstract}

\section{MATERIALS AND METHODS}

It is a cross-sectional study, hospital-based assessment conducted at the Department of Obstetrics and Gynaecology at IRT Perundurai Medical College. A total of 37 consecutive sampling of healthy postmenopausal participants who presented in the outpatient department were included in the study. All the 37 study participants filled out the Pittsburgh Sleep Quality Index (PSQI) providing data for statistical analysis. The age of participants ranged from 37 to 55 years. Women receiving hormonal treatment, having serious medical comorbidities such as thyroid disorders, cardiovascular disorders, diabetes mellitus, serious axis 1 psychiatric morbidity receiving treatment, hypertension and those who refused to participate were not included. PSQI was used to assess the sleep pattern in postmenopausal study population producing 7 components scores and one global score.

\section{RESULTS}

Among 70 women screened, 37 women fulfilled the inclusion and exclusion criteria. The average global score is 4.83 , which very well segregates the sleep impairment in this subgroup. Age is positively correlated with global score and parity is negatively correlated with global score. Among the individual component score, daytime dysfunction positively correlates with age and negatively correlates with parity.

\section{CONCLUSION}

Sleep impairments were highly prevalent, often underdiagnosed with sleep quality index well below the normal.

\section{KEYWORDS}

Sleep, Insomnia, Menopause, Post-Menopause, Pittsburgh Sleep Quality Index.

HOW TO CITE THIS ARTICLE: Indira M, Kasikrishnaraja P. Patterns of sleep impairments in an epidemiological cohort of postmenopausal women in Perundurai. J. Evolution Med. Dent. Sci. 2018;7(16):1955-1961, DOI: 10.14260/jemds/2018/440

\section{BACKGROUND}

Menopause [(Greek: mene (Month); pausis (Stop)], defined as the cessation of menstrual period, physiologically it results from the natural depletion of ovarian follicular function; a condition that translates into permanent amenorrhoea (the permanent cessation of menstrual flow) generally associated with aging.

The signs and symptoms of menopause are characterised by onset of irregular menses, hot flushes and night sweats. Menopause is known to be associated with changes in biopsychosocial changes, e.g. mood swings, anxiety, sexual dysfunction, stress, forgetfulness and sleep disturbances.

'Financial or Other Competing Interest': None.

Submission 09-03-2018, Peer Review 02-04-2018,

Acceptance 09-04-2018, Published 16-04-2018.

Corresponding Author:

Dr. P. Kasikrishnaraja,

A2, SMQ, Sanatorium,

Perundurai, Erode District,

Tamilnadu.

E-mail:drkasi@gmail.com

DOI: $10.14260 /$ jemds $/ 2018 / 440$

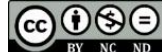

During menopause oestrogen levels decline, leading on sleep impairment, depressive disorders, cognitive decline and various physical ailments like osteoporosis, vaginal atrophy, sexual dysfunction, etc.

Sleep epoch is different for male and female gender across lifespan, and this may result from the influence of female gonadotropic hormones on sleep.[1] Women have more sleep impairments as women's sleep is not only influenced by the gonadotropins themselves, but also by the milestones related to these hormones, e.g. pregnancy, lactation, menopause etc.

Sleep disturbances among menopausal women have been ascribed to a number of factors, e.g. normal physiological changes associated with aging, poor health perception, menopausal-related symptoms, poor sleep hygiene, nervousness, stress, mood symptoms (e.g. depression and anxiety) and comorbid chronic health issues.[2-5]

Besides these biological and chronobiological factors, socioeconomic, psychosocial, cultural and race/ ethnic factors might also play an interacting role between the sleep and menopause.[6-7] 
Postmenopausal women may have a number of sleep disorders including insomnia, obstructive sleep apnoea (OSA) and restless legs syndrome (RLS) to name a few. Having this background in mind, we will try to explore the factors that may be related to the sleep disturbances seen among menopausal women in this review.

The diagnosis of insomnia includes difficulty in initiating sleep, maintaining sleep or experiencing non-restorative sleep despite adequate opportunity for sleep. Daytime sleep related functional impairments resulting from nocturnal sleep disturbance must also be reported.

Postmenopausal women have been found to report subjective poor quality sleep even when the polysomnography examination shows higher amounts of deep sleep and longer sleep times as compared to premenopausal women. It may be deduced that multiple other yet to be found factors in addition to menopause status may affect the sleep quality.

Just like most of the developing countries, it is difficult for women living in rural India to obtain access to healthcare services, particularly access to mental health care for sleep issues and this is due to insufficient numbers of mental healthcare personnel, reduced quality of healthcare services, difficulties in accessing care due to economic reasons, low education level and low socioeconomic status. The prevalence of inability to access health care services is a gender issue in India.

Determining the applicability of the PSQI as a screening test for rural women would assist rural healthcare workers to identify women with severe sleep issues comorbid with menopausal symptoms and to refer them to secondary level or tertiary care physicians (Gynaecologists/ Psychiatrists) for appropriate medical attention.

In summary, postmenopausal women have increased sleep impairments during the menopausal transition and post menopause. Sleep disturbance during the menopausal transition is likely to be multifactorial with changes in reproductive hormones, aging, lifestyle and bidirectional relationship with physical and psychiatric conditions, all playing roles.

\section{Review of Literature}

Menopause is defined as the cessation of menstruation for at least 1 year due to degeneration of ovaries and follicles and changing ovarian hormone levels. Decreased ovarian function precedes menopause in the climacteric or perimenopausal period along with menstrual cycle changes and vasomotor symptoms, typically beginning gradually long before menses cease. The worldwide population of 470 million postmenopausal women is increasing- 1.5 million women enter menopause yearly and is expected to reach 1.2 billion by 2030.[8] The American Psychiatric Association (2000) defined sleep disorder as the difficulty to initiate and/or maintain sleep during a period of at least 3 weeks.

Indian Menopause Society reports there were about 65 million Indian women over the age of 45 years in the year 2006. Hence, menopausal health in Indian scenario demands higher resource. In India, there is a big gap in achieving specific health care for postmenopausal issues. This study is expected to bring out the magnitude of insomnia among postmenopausal women, which can be addressed at proper healthcare platform among this important subgroup of women.

Sleep is extremely relevant factor in the preservation of health and strongly impacts quality of life during aging. A study by Vigeta and Brêtas (2004)[9] found that women experienced alterations in sleep following menopause. The postmenopausal period begins 1 year after the last menstrual bleeding and is a biological milestone regardless of whether menopause was natural or induced.

Insomnia is one of the most common symptoms reported by postmenopausal women (Goberna, Francés, Paulí, Barluenga and Gascón, 2009).[10] Sleep disturbances after menopause is a common medical issue. Leger et al[11] reported in their questionnaire study with over 12,000 participants of both sexes, that $15 \%$ of women over 50 years, but only $5 \%$ of women aged $18-24$ suffered from severe insomnia.

Complaints of sleep disturbance, usually in the form of intermittent awakenings, often accompany menopause. Large population-based studies suggest that $28 \%$ to $64 \%$ of perimenopausal or postmenopausal women report sleep disturbance.[12,13] Polysomnography (PSG) studies document reduced sleep efficiency with sleep initiation and maintenance of difficulties in postmenopausal versus premenopausal women.[14,15]

Jean-Louis et al[16] obtained 24-hour polysomnographic recordings data from 154 women aged 51 to 81 (mean 66.7). They were analysed using an Actillume monitor on the wrist (Ambulatory Monitoring, Inc., Ardsley, NY) for 7 days. Older women slept an average of 439 minutes over 24 hours with $10 \%$ of sleep time recorded out of bed. Older women had more afternoon-evening sleep, but some women even slept shortly after arising in the morning.

In a large epidemiologic study of premenopausal, perimenopausal and postmenopausal women, sleep was measured with subjective report and objective PSG measurement.[17] Menopausal status was moderately related to self-reported sleep dissatisfaction, but objective sleep quality was not worse in perimenopausal or postmenopausal women than in premenopausal women. In fact, postmenopausal women had more deep sleep and significantly longer total sleep time.

In 21 premenopausal (age 45 - 51), 29 postmenopausal (age 59 - 71) and 11 young (age 20 - 26) women, Kalleinen et al[18] recorded objective sleep quality with PSG as well as subjective sleep quality, sleepiness and mood. Although, insomnia complaints were more frequent in menopause, the older groups had less total sleep time and lower sleep efficiency. The REM latency in postmenopausal women was shorter than that in young women. Pre- and post-menopausal women had more awakenings than young women. They had more awakenings from S2, SWS [SWS; stage 3 (S3) and stage 4 (S4) combined] and from REM sleep. In the postmenopausal group, there were also more awakenings from $\mathrm{S} 1$ than in the young group.

\section{MATERIALS AND METHODS}

This is a cross-sectional interview based descriptive study, which was conducted in the small town of Perundurai from a cohort of postmenopausal women attending the OPD of IRT Perundurai Medical College. The study was conducted for a 
period of three months from September to November of 2017.

Consecutive sampling was chosen among the women who fulfilled the criteria for postmenopausal state. Inclusion criteria for the study were women who were amenorrhoeic for the past 1 year and those women who had attained natural menopause during the last 5 years. Postmenopausal women who have attained menopause during the last 5 years were included in the study to minimise the recall bias if any.

Exclusion criteria was those who did not consent and serious medical comorbidities like diabetes, cardiovascular diseases etc. and women who suffer from serious psychiatric comorbidity.

A total of seventy postmenopausal women were approached for interview and among them 37 women fulfilled the inclusion criteria and so were included in the study. The total duration of amenorrhoea was determined and mean duration of menopausal period was also determined.

\section{Menopausal Status Definitions}

Concerning the menopausal status, the following definitions were used: Premenopausal (women having regular menses and $\geq 12$ menses during the last 12 months); perimenopausal (irregular menses, less than 12 menses during the last 12 months) and postmenopausal (no more menses in the last 12 months).

The Study Instruments consisted of Pre-Tested SemiStructured Interview Based Oral Questionnaire. The Components of the Questionnaire were as follows-

1. A pre-tested semi-structured questionnaire was used to assess the socio-demographic profile of the study population.

2. Age at attaining the menopause was determined and the duration of the menopausal period till the current study period was included.

3. Socioeconomic status scale by modified Kuppuswamy (1976) was used to assess the socioeconomic status of the study population.

4. Pittsburgh Sleep Quality Index (PSQI) was used to assess the sleep dysfunction. PSQI is a self-rated questionnaire, among which 19 were self-rated and five were rated by the bed partner. Nineteen individual items generate seven component scores: Subjective sleep quality, sleep latency, sleep duration, habitual sleep efficiency, sleep disturbances, use of sleeping medication and daytime dysfunction. The sum of the seven component score yields one composite global score. The PSQI global score has a possible range of $0-21$ points. PSQI assesses the retrospective 1-month period.

5. Socio-economic parameters like occupation, religious status, education and income level were collected. Informed consent and ethical clearance were obtained.

\section{Statistical Analysis}

Analysis was done using the statistical version 8. The frequencies like mean, median, mode, sum and quartiles were calculated for the socio-demographic data. Pearson's Correlation was obtained between age and total score, parity vs. global score. A cross-tabulation and frequency tabulations were calculated.

\section{RESULTS}

The age range of the study population was between 37 years to 55 years with $52 \%$ of the study subjects falling within 48 years, which is a relatively younger age predominant postmenopausal sample. $37 \%$ of the study subjects fell within a narrow range of 48 to 50 years. The mean age is 48.5 years. The median age and the mode is the same 48 years (Figure 1) and (Table 1a).

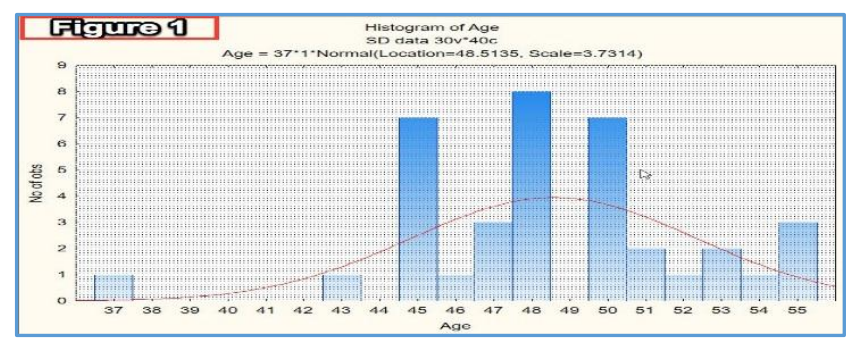

The mean parity is 2.1 and the median and mode for the parity data is 2 . Among the study group, $57 \%$ of women had a parity of 2 children (Table 2) and (Figure 3 ).

\begin{tabular}{|l|r|c|r|r|}
\hline \multirow{3}{*}{ Table 2 } & Frequency table: Parity (SD data) & \\
\cline { 2 - 5 } Parity & Count & \multicolumn{1}{c|}{$\begin{array}{c}\text { Cumulative } \\
\text { Count }\end{array}$} & Percent & $\begin{array}{c}\text { Cumulative } \\
\text { Percent }\end{array}$ \\
\hline 0 & 1 & 1 & 2.50000 & 2.5000 \\
\hline 1 & 4 & 5 & 10.00000 & 12.5000 \\
\hline 2 & 23 & 28 & 57.50000 & 70.0000 \\
\hline 3 & 7 & 35 & 17.50000 & 87.5000 \\
\hline 4 & 2 & 37 & 5.00000 & 92.5000 \\
\hline \hline Missing & 3 & 40 & 7.50000 & 100.0000 \\
\hline
\end{tabular}

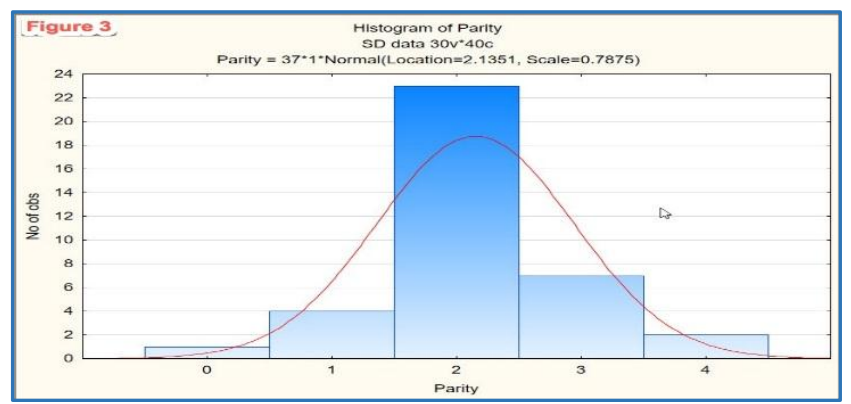

The mean duration of years since menopause is 3.14 years (Table 1a).

\begin{tabular}{|c|c|c|c|c|c|c|c|c|c|c|}
\hline \multirow[b]{2}{*}{$\begin{array}{l}\text { Table ta, } \\
\text { Variable }\end{array}$} & \multicolumn{10}{|c|}{ Descriptive Statistics (Socio demographic data) } \\
\hline & Valid N & Mean & Median & Mode & $\begin{array}{c}\text { Frequency } \\
\text { of Mode }\end{array}$ & Minimum & Maximum & Variance & 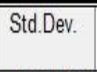 & Skewness \\
\hline Age & 37 & 48.51351 & 48.00000 & 48.00000 & 8 & 37.00000 & 55.00000 & 13.92342 & 3.731410 & -0.43193 \\
\hline SEscale & 37 & 3.45946 & 4.00000 & 4.000000 & 21 & 1.00000 & 5.00000 & 0.69970 & 0.836481 & -1.06912 \\
\hline Parity & 37 & 2.13514 & 2.00000 & 2.000000 & 23 & 0.00000 & 4.00000 & 0.62012 & 0.787477 & 0.11175 \\
\hline Attainedmenopause & 37 & 3.14324 & 3.00000 & 2.000000 & 10 & 0.30000 & 5.00000 & 1.68141 & 1.296692 & -0.10510 \\
\hline
\end{tabular}


$52 \%$ of women were from class IV of the socioeconomic class (Upper lower) and another $25 \%$ of women were from class III of the socioeconomic class (Lower middle). So the overwhelming majority were from the lower income group (Table 4) and (Figure 5).

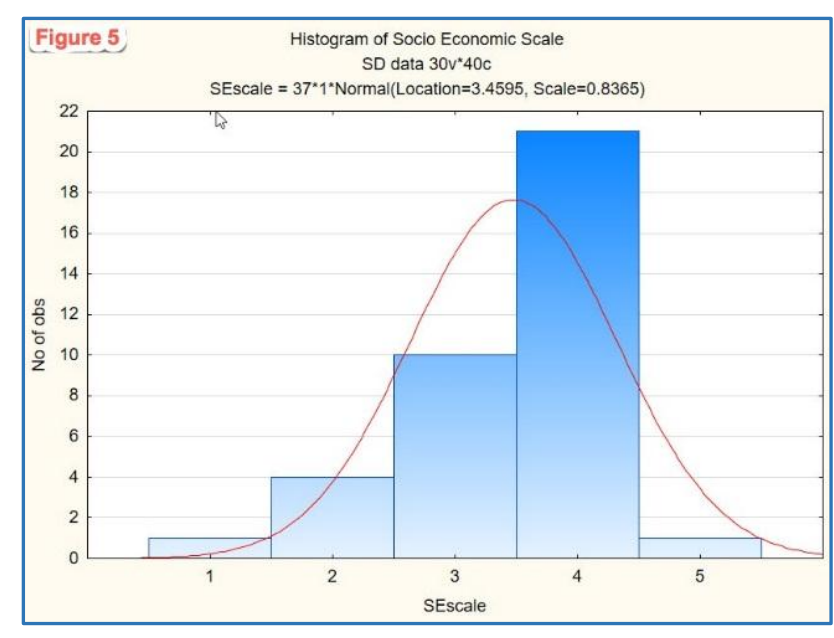

\begin{tabular}{|c|c|c|c|c|}
\hline \multirow{2}{*}{$\begin{array}{l}\text { Table 4 } \\
\text { SE Scale }\end{array}$} & \multicolumn{4}{|c|}{ Frequency table: SEscale (SD data) } \\
\hline & Count & $\begin{array}{c}\text { Cumulative } \\
\text { Count }\end{array}$ & Percent & $\begin{array}{c}\text { Cumulative } \\
\text { Percent }\end{array}$ \\
\hline 1 & 1 & 1 & 2.50000 & 2.5000 \\
\hline 2 & 4 & 5 & 10.00000 & 12.5000 \\
\hline 3 & 10 & 15 & 25.00000 & 37.5000 \\
\hline 4 & 21 & 36 & 52.50000 & 90.0000 \\
\hline 5 & 1 & 37 & 2.50000 & 92.5000 \\
\hline Missing & 3 & $\overline{40}$ & 7.50000 & 100.0000 \\
\hline
\end{tabular}

The age of the study subjects was positively correlated with the global PSQI score (0.0192) with a significance of ' $p$ ' less than 0.05 . This means higher the study subject's age, the more the global PSQI score (Figure 6) and (Table 8).

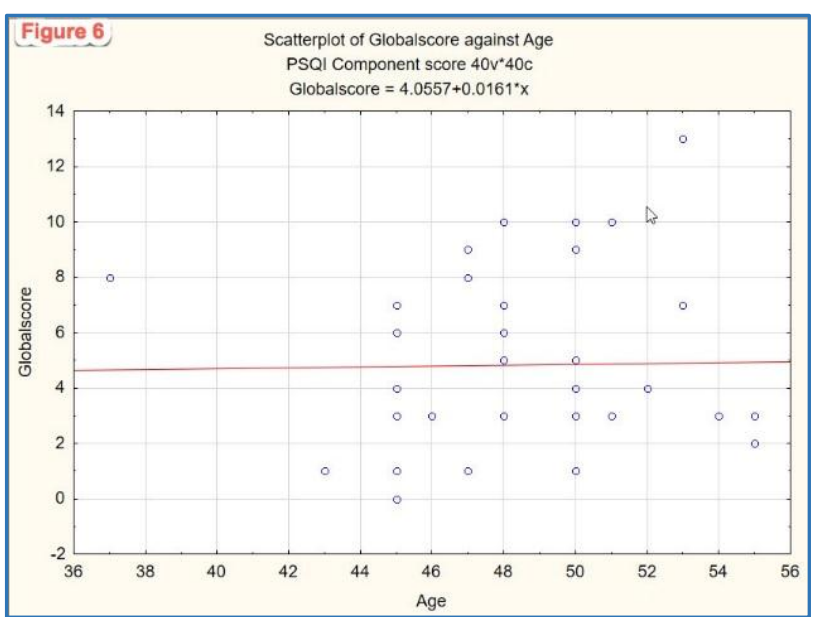

\begin{tabular}{|c|c|c|c|c|c|}
\hline \multirow{2}{*}{\begin{tabular}{|l|} 
Table 8 \\
Variable
\end{tabular}} & \multicolumn{5}{|c|}{$\begin{array}{l}\text { Correlations (Age Vs Parity Vs Global score) } \\
\text { Marked correlations are significant at } p<.05000 \\
N=37 \text { (Casewise deletion of missing data) }\end{array}$} \\
\hline & Means & Std.Dev. & Age & parity & Globalscore \\
\hline Age & 48.51351 & 3.731410 & 1.000000 & -0.024272 & 0.01921 \\
\hline parity & 2.13514 & 0.787477 & -0.024272 & 1.000000 & -0.080982 \\
\hline Globalscore & 4.83784 & 3.131502 & 0.019211 & -0.080982 & 1.000000 \\
\hline
\end{tabular}

The parity status is negatively correlated $(-0.080)$ with the Global PSQI score. This means higher the parity, less is the Global PSQI score (Figure 8). Also, the age and parity was also negatively correlated $(-0.02)$ (Table 8 ).

The mean global score of the PSQI rating is 4.83 (Table 7).

\begin{tabular}{|c|c|c|c|c|c|c|c|c|c|c|}
\hline \multirow{2}{*}{$\begin{array}{l}\text { Table } 7 \text {, } \\
\text { Variable }\end{array}$} & \multicolumn{10}{|c|}{ Descriptive Statistics (PSQI Component score) } \\
\hline & Valid $\mathrm{N}$ & Mean & Median & Mode & $\begin{array}{c}\text { Frequency } \\
\text { of Mode }\end{array}$ & Minimum & Maximum & Variance & Std.Dev. & Skewness \\
\hline C1subslpquality & 37 & 0.756757 & 1.000000 & 0.000000 & 18 & 0.00 & 2.00000 & 0.689189 & 0.830174 & 0.49465 \\
\hline C2siplatency & 37 & 1.405405 & 1.000000 & 1.000000 & 14 & 0.00 & 3.00000 & 1.303303 & 1.141623 & 0.30534 \\
\hline C3sipduration & 37 & 0.756757 & 1.000000 & 0.000000 & 16 & 0.00 & 3.00000 & 0.633634 & 0.796011 & 0.82546 \\
\hline C4habslpefficiency & 37 & 0.243243 & 0.000000 & 0.000000 & 30 & 0.00 & 2.00000 & 0.300300 & 0.547997 & 2.24454 \\
\hline C5stepdisturbances & 37 & 0.918919 & 1.000000 & 1.000000 & 32 & 0.00 & 2.00000 & 0.132132 & 0.363500 & -1.11470 \\
\hline C6useofmedication & 37 & 0.135135 & 0.000000 & 0.000000 & 32 & 0.00 & 1.00000 & 0.120120 & 0.346583 & 2.22581 \\
\hline C7daytimedysfn & 37 & 0.594595 & 1.000000 & 1.000000 & 18 & 0.00 & 2.00000 & 0.358859 & 0.599048 & 0.43404 \\
\hline Globalscore & 37 & 4.837838 & 4.000000 & 3.000000 & 10 & 0.00 & 13.00000 & 9.806306 & 3.131502 & 0.71518 \\
\hline
\end{tabular}

The mean global score is 4.83 and median global score is 4. The overall global score ranged between 0 and $13 ; 48 \%$ of the study subjects had a global score of above 5 . The frequency range, percentage of the global score and the cumulative percentage of the global score is calculated in the Table 5 and Figure 7.

Table 7 also reveals median sleep duration score is 1 , that means an average sleep duration between $6-7$ hours. The mean sleep duration score is also 0.75 , that again extrapolates into 6 - 7 hours of sleep.

The median habitual sleep efficiency score is 0 , that means the habitual sleep efficiency is more than $85 \%$. The mean habitual sleep efficiency score is also 0.24 , that again indicates the habitual sleep efficiency is more than $85 \%$.

\begin{tabular}{|l|r|r|r|r|}
\hline \multirow{3}{*}{ Global sable 5 } & \multicolumn{5}{|c|}{ Frequency table: Globalscore (PSQ| Component score } \\
\cline { 2 - 5 } & Count & \multicolumn{1}{c|}{$\begin{array}{c}\text { Cumulative } \\
\text { Count }\end{array}$} & Percent & $\begin{array}{c}\text { Cumulative } \\
\text { Percent }\end{array}$ \\
\hline 0 & 1 & 1 & 2.50000 & 2.5000 \\
\hline 1 & 4 & 5 & 10.00000 & 12.5000 \\
\hline 2 & 2 & 7 & 5.00000 & 17.5000 \\
\hline 3 & 10 & 17 & 25.00000 & 42.5000 \\
\hline 4 & 4 & 21 & 10.00000 & 52.5000 \\
\hline 5 & 3 & 24 & 7.50000 & 60.0000 \\
\hline 6 & 2 & 26 & 5.00000 & 65.0000 \\
\hline 7 & 3 & 29 & 7.50000 & 72.5000 \\
\hline 8 & 2 & 31 & 5.00000 & 77.5000 \\
\hline 10 & 2 & 33 & 5.00000 & 82.5000 \\
\hline 13 & 3 & 36 & 7.50000 & 90.0000 \\
\hline \hline Missing & 1 & 37 & 2.50000 & 92.5000 \\
\hline
\end{tabular}




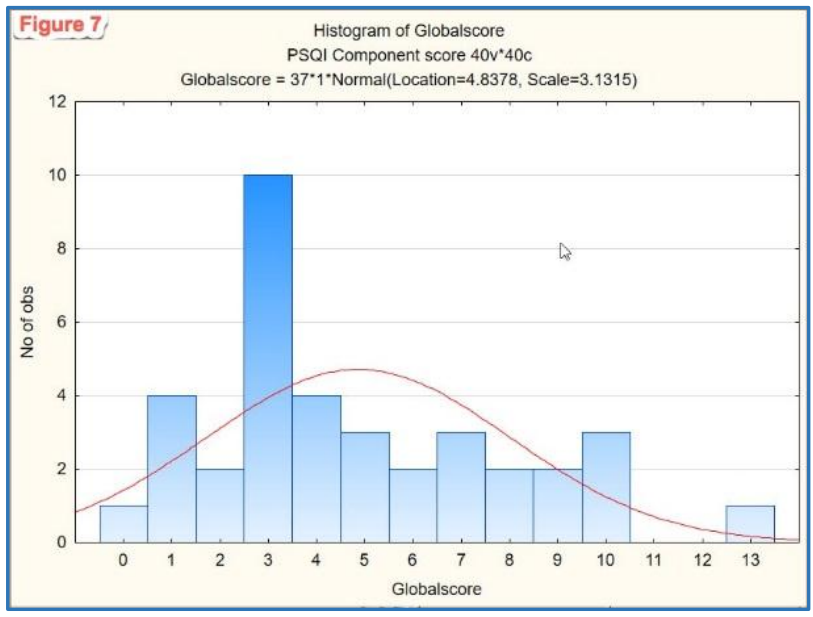

The variability of global score against age was calculated and a global score of 5 fell within a narrow age range of 48 to 50 years and more the global score the more the variability of the age.
For e.g. a global score of 8 fell between the age ranges 37 and 47. Also lesser the global score more it fell within a wider age range, e.g. a global score of 3 fell between the age range 45 and 55 years (Figure 8).

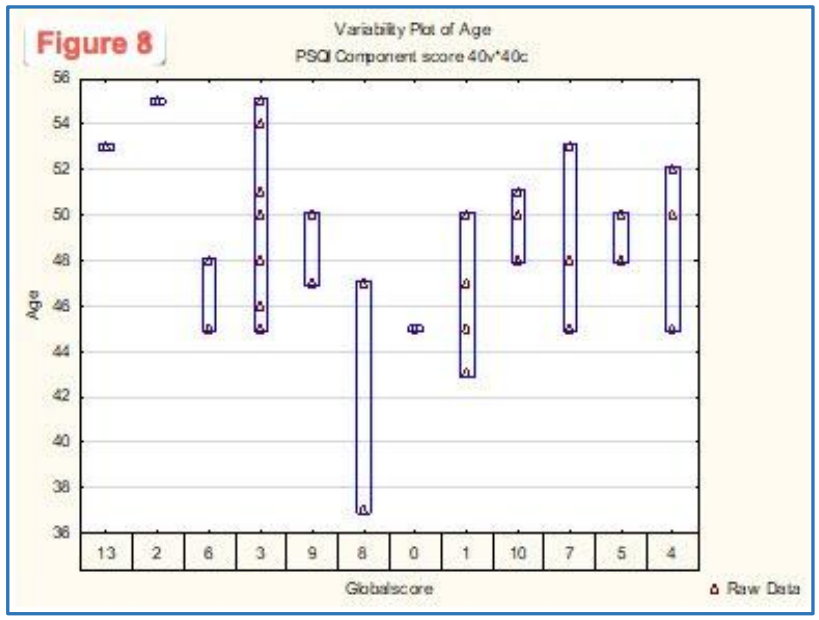

\begin{tabular}{|l|r|r|r|r|}
\hline \hline \multirow{2}{*}{ Table 9j } & \multicolumn{4}{|l|}{$\begin{array}{l}\text { Correlations of Component scores with Age, parity, SE scale and menopausal duration } \\
\text { Marked correlations are significant at } p<.05000\end{array}$} \\
& $N=37$ (Casewise deletion of missing data) \\
\cline { 2 - 5 } Variable & Attainedmeno & \multicolumn{1}{c|}{ Age } & \multicolumn{1}{c|}{ parity } & SEscale \\
\hline C1subsipquality & 0.007462 & -0.200671 & 0.009187 & -0.154599 \\
\hline C2slplatency & -0.272999 & -0.239331 & -0.031734 & 0.003145 \\
\hline C3slpduration & -0.191364 & 0.146094 & -0.079047 & -0.119516 \\
\hline C4habslpefficiency & -0.222399 & 0.168155 & -0.013918 & 0.113009 \\
\hline C5stepdisturbances & 0.025325 & 0.215865 & -0.154741 & 0.217279 \\
\hline C6useofmedication & -0.106078 & -0.076628 & -0.068769 & -0.220116 \\
\hline C7daytimedysfn & -0.162757 & 0.344259 & -0.116177 & 0.104876 \\
\hline
\end{tabular}

Table 9 shows the Pearson's correlation between the variables Age, Parity and Socioeconomic scale and the individual component scores of the Pittsburgh scale. As it can be seen the individual component of daytime dysfunction positively correlates with age, but negatively correlates with parity. The component score habitual sleep efficiency positively correlates with age. Sleep latency negatively correlates with both age and parity. The total sleep duration score positively correlates with age, higher the score lesser the sleep duration. Hence, the sleep duration decreases with higher the age.

\section{DISCUSSION}

As women enter the transition phase of menopause, there will be significant changes in their gonadal hormones. There will be an increase in FSH and a decline in oestrogen relative to premenopause. Many women develop many somatic and psychological symptom cluster called postmenopausal syndrome. Among the PMS decline in sleep quality and sleep duration, hot flushes, anxiety and depression are common. Several studies have investigated the impact of the menstrual cycle on sleep in postmenopausal women, increased frequency of restless leg syndrome, sleep disordered breathing, increased fragmentation of sleep, reduced total sleep duration, decreased sleep efficiency, daytime dysfunction and nocturnal hot flushes all contribute to the sleep impairment in postmenopausal women. Age also has a natural effect on the sleep. As age increases one tend to have a decreased, slow wave sleep and REM sleep.

Sleep complaints increase manifold during menopausal transition and postmenopausal phase in women with the prevalence increasing from $12 \%$ to $40 \%$ in women during the late 40 s and early 50 s.[19]

In epidemiological studies, documenting the presence of an insomnia syndrome. Peri and early postmenopausal women are more likely to meet criteria for an insomnia disorder than older reproductive age women $(26 \%$ versus $13 \%)$. The attrition in the gonadal hormone levels during the postmenopausal phase was associated with differences in the sleep quality and objectively measured sleep parameters.

Primary sleep disorders such as obstructive sleep apnoea, Restless leg syndrome and periodic limb movement disorder are common in postmenopausal women and contribute to the increased prevalence of sleep impairments in this population. The overall prevalence of obstructive sleep apnoea is estimated at $9 \%$ in women, but this prevalence increases as women transition into midlife with the prevalence increasing from $6.5 \%$ to $8.7 \%$ to $16 \%$ in women in their 30 s, 40 s and 50s, respectively.[20]

Although, sleep impairments in perimenopausal women is associated with the gonadal hormones attrition, sleep complaints in this population also correlate with age-related sleep impairments and with medical comorbidities that increases during postmenopausal life.[21] Common medical 
morbidities that may affect sleep that increase with age include obesity, ${ }^{[22]}$ cancer, ${ }^{[23]}$ gastro-oesophageal reflux, ${ }^{[24]}$ urinary incontinence and nocturnal micturition,[25,26-27] thyroid dysfunction, ${ }^{[28]}$ chronic pain syndromes[29] and fibromyalgia.[30] As women transition into middle age, increased use of psychopharmacological interventions for treating psychiatric comorbidities also contribute to sleep impairments.

Other causes of sleep impairments in postmenopausal women that may contribute to significant sleep disruption include poor sleep hygiene (i.e. irregular sleep-wake schedule, Gadget addiction, game addiction, excessive caffeine), decreased sleep duration due to volitional factors (i.e. increased sleep latency or rising early by choice or to meet work or social obligations) and environmental disturbances (e.g. snoring bed partner, noise and light pollution, crowded environment).

For global and component scores on the PSQI, higher scores indicate more severe complaints. The global score and age of the study group is positively correlated indicating a more subjective sleep impairment in elderly age group.

In the work done by Daniel J. Buysse et al a global PSQI score of 5 less than or equal correctly identified 84, 4\% of insomnia patients. Applying this categorical criterion to the current sample, the average global score is 4.83 , which again predicts the overall reduction in sleep quality.

It is possible that age-related changes in subjective sleep quality are explained more by the concomitants of old age, such as medical comorbidities, climacteric hormonal changes, medication use or comorbid psychiatric morbidities like depression and anxiety than by age per se. Circadian sleep related disorder may also contribute to the overall sleep impairments score.

\section{CONCLUSION}

In summary, sleep impairments in postmenopausal women are common in this cohort collected in a small town of Perundurai. This was associated with the menopause transition itself, higher the postmenopausal age more is the sleep impairment, lesser the parity more is the sleep impairment. Climacteric symptoms of hot flashes, aging, primary sleep disorders, circadian sleep disorders, comorbid medical conditions and medications, poor sleep hygiene, hormonal factors of climacteric as well as with psychosocial and behavioural factors contribute to the sleep impairments. Practitioners of reproductive and women's health should be aware of the prevalence of sleep impairments in this population and refer this important subgroup of women for evaluation if a sleep disorder is suspected. Effective means are available for treating the sleep disorders and the comorbidities that contribute to this. If treated, substantial improvements in quality of life and health outcome is possible. Careful evaluation of this postmenopausal subgroup of women will throw light on the underlying causes, which will aid in the determination of treatment strategies.

\section{REFERENCES}

[1] Walsleben J. Women and sleep. Handbook of Clinical Neurology 2011: p. 639-651.
[2] Albuquerque RG, Hachul H, Andersen ML, et al. The importance of quality of sleep in menopause. Climacteric 2014;17(5):613-3.

[3] Hachul H, Andersen ML, Bittencourt LR, et al. Does the reproductive cycle influence sleep patterns in women with sleep complaints? Climacteric 2010;13(6):594603.

[4] Kravitz H, Ganz P, Bromberger J, et al. Sleep difficulty in women at midlife: a community survey of sleep and the menopausal transition. Menopause 2003;10(1):19-28.

[5] Sun D, Shao H, Li C, et al. Sleep disturbance and correlates in menopausal women in Shanghai. Journal of Psychosomatic Research 2014;76(3):237-41.

[6] Moreno-Frías C, Figueroa-Vega N, Malacara JM. Relationship of sleep alterations with perimenopausal and postmenopausal symptoms. Menopause 2014;21(9):1017-22.

[7] Ornat L, Martínez-Dearth R, Chedraui P, et al. Assessment of subjective sleep disturbance and related factors during female mid-life with the Jenkins Sleep Scale. Maturitas 2014;77(4):344-50.

[8] World Health Organization. Research on the menopause in the 1990s. Report of a WHO Scientific Group. World Health Organ Tech Rep Ser 1996;866:1 107.

[9] Vigeta SMG, Brêtas ACP. Peri-menopausal and postmenopausal experience among women with and without hormone replacement therapy. Cadernos de Saúde Pública 2004;20(6):1682-9. doi:10.1590/s0102-311x 200400060002.

[10] Goberna J, Francés L, Paulí A, et al. Sexual experiences during the climacteric years: What do women think about it? Maturitas 2009;62(1):47-52. doi:10.1016/j.maturitas.2008.10.007.

[11] Leger D, Guilleminault C, Dreyfus JP, et al. Prevalence of insomnia in a survey of 12,778 adults in France. J Sleep Res 2000;9(1):35-42.

[12] Ohayon MM. Severe hot flashes are associated with chronic insomnia. Arch Intern Med 2006;166(12):1262-8.

[13] Polo-Kantola P, Saaresranta T, Polo O. Aetiology and treatment of sleep disturbances during perimenopause and postmenopause. CNS Drugs 2001;15(6):445-52.

[14] de Campos HH, Brandao LC, D’Almeida V, et al. Sleep disturbances, oxidative stress and cardiovascular risk parameters in postmenopausal women complaining of insomnia. Climacteric 2006;9(4):312-19.

[15] Shaver JL, Giblin E, Paulsen V. Sleep quality subtypes in midlife women. Sleep 1991;14(1):18-23.

[16] Jean-Louis G, Kripke DF, Assmus JD, et al. Sleep wake patterns among postmenopausal women: a 24-hour unattended polysomnographic study. J Gerontol A Biol Sci Med Sci 2000;55(3):M120-M3.

[17] Young T, Rabago D, Zgierska A, et al. Objective and subjective sleep quality in premenopausal, perimenopausal and postmenopausal women in the Wisconsin Sleep Cohort Study. Sleep 2003;26(6):66772. 
[18] Kalleinen N, Polo-Kantola P, Himanen SL, et al. Sleep and the menopause - do postmenopausal women experience worse sleep than premenopausal women? Menopause Int 2008;14(3):97-104.

[19] Joffe H, Massler A, Sharkey KM. Evaluation and management of sleep disturbance during the menopause transition. Seminars in Reproductive Medicine 2010;28(5):404-21. doi:10.1055/s-00301262900

[20] Young T, Palta M, Dempsey J, et al. The occurrence of sleep-disordered breathing among middle-aged adults. N Engl J Med 1993;328(17):1230-5.

[21] Berecki-Gisolf J, Begum N, Dobson AJ. Symptoms reported by women in midlife: menopausal transition or aging? Menopause 2009;16(5):1021-9.

[22] Patel SR, Blackwell T, Redline S, et al. The association between sleep duration and obesity in older adults. Int J Obes (Lond) 2008;32(12):1825-34.

[23] Stepanski EJ, Walker MS, Schwartzberg LS, et al. The relation of trouble sleeping, depressed mood, pain, and fatigue in patients with cancer.J Clin Sleep Med 2009;5(2):132-6.

[24] Mody R, Bolge SC, Kannan H, et al. Effects of gastroesophageal reflux disease on sleep and outcomes. Clin Gastroenterol Hepatol 2009;7(9): 953-9.
[25] Asplund R, Aberg H. Nocturnal micturition, sleep and well-being in women of ages 40-64 years. Maturitas 1996;24(1-2):73-81.

[26] Asplund R, Aberg HE. Nocturia and health in women aged 40-64 years. Maturitas 2000;35(2):143-8.

[27] Alexander JL, Neylan T, Kotz K, et al. Assessment and treatment for insomnia and fatigue in the symptomatic menopausal woman with psychiatric comorbidity. Expert Rev Neurother 2007;7(Suppl 11):S139-S55.

[28] Winkelman JW, Goldman H, Piscatelli N, et al. Are thyroid function tests necessary in patients with suspected sleep apnea? Sleep 1996;19(10):790-3.

[29] Fishbain DA, Cole B, Lewis JE, et al. What is the evidence for chronic pain being etiologically associated with the DSM-IV category of sleep disorder due to a general medical condition? A structured evidence-based review. Pain Med 2010;11(2):158-79.

[30] Chervin RD, Teodorescu M, Kushwaha R, et al. Objective measures of disordered sleep in fibromyalgia. J Rheumatol 2009;36(9):2009-16. 